\title{
Recombination at textured silicon surfaces passivated with silicon dioxide
}

\author{
Keith R. McIntosh ${ }^{\mathrm{a})}$ and Luke P. Johnson \\ Centre for Sustainable Energy Systems, Australian National University, Canberra, \\ Australian Capital Territory 2600, Australia
}

(Received 10 April 2009; accepted 21 May 2009; published online 25 June 2009)

\begin{abstract}
The surfaces of solar cells are often textured to increase their capacity to absorb light. This optical benefit is partially offset, however, by an increase in carrier recombination at or near the textured surface. A review of past work shows that the additional recombination invoked by a textured surface varies greatly from one experiment to another. For example, in the most commonly investigated structure - pyramidal textured silicon diffused with phosphorus and passivated with a hydrogenated oxide - recombination ranges from being 1-12 times more than in an equivalently prepared planar $\{100\}$ surface. Examination of these experiments reveals consistent trends: small increases in recombination occur when the surface is very heavily diffused and dominated by Auger recombination, while larger increases in recombination occur when the surface is lightly diffused and dominated by Shockley-Read-Hall recombination at the surface, making the latter depend critically on surface area and the density of surface states. Comparisons of pyramidal and planar $\{100\}$ surfaces indicate that when lightly diffused, the difference in recombination is substantially greater than the difference in surface area (1.73) and it is regularly attributed to the pyramid facets having $\{111\}$ orientations-well known for their higher density of dangling bonds than $\{100\}$ orientations. This high dangling-bond density makes recombination at pyramidal facets strongly dependent on the passivation scheme, and it is variations in these schemes that led to the wide range of results observed in experimental studies. In addition to surface area and crystal orientation, some experiments suggest a third mechanism that enhances recombination on oxide-passivated pyramids. With capacitance-voltage and photoconductance measurements, we confirm this speculation, showing that oxide-passivated pyramidal textured silicon has a higher density of interface states than can be accounted for by surface area and orientation, and that the additional defects are predominantly acceptorlike when above, or donorlike when below, an energy of $0.3 \mathrm{eV}$ higher than the valence band. (C) 2009 American Institute of Physics. [DOI: 10.1063/1.3153979]
\end{abstract}

\section{INTRODUCTION}

A solar cell absorbs more sunlight when its front surface is textured rather than planar. Figure 1 illustrates how a textured facet can reflect incident rays onto a neighboring facet, giving the light two (or sometimes more) opportunities to be transmitted into the cell's absorber. Texture also aids absorption by increasing a cell's capacity to "trap" transmitted light within its absorber. Seminal work on these subjects can be found in Refs. 1-4.

Solar cells were first textured in the 1960s using ultrasonic etches. ${ }^{5}$ Texturing did not become common, however, until the 1970s (Refs. 1 and 5) following the development of anisotropic wet etches. ${ }^{6}$ Today, all commercial monocrystalline silicon cells [38\% of the global market in 2008 (Ref. 7)] are textured by anisotropic wet alkaline etchants such as $\mathrm{KOH},{ }^{8,9} \quad \mathrm{~K}_{2} \mathrm{CO}_{3},{ }^{10,11} \mathrm{Na}_{2} \mathrm{CO}_{3},{ }^{12-14} \mathrm{NaOH},{ }^{15-17}$ and $\left(\mathrm{CH}_{3}\right)_{4} \mathrm{NOH}$ (TMAH). ${ }^{18-21}$ These solutions etch $\{111\}$ planes many times more slowly than other crystal planes, ${ }^{6,22,23}$ a feature that can be exploited to form pyramids, inverse pyramids, and slats into the surface of silicon.

Commercial monocrystalline solar cells are textured with randomly distributed upright tetrahedral pyramids called "rantex" [Fig. 2(a)]. The pyramids consist of four $\{111\}$ (or near $\{111\}$ ) planes and four $\langle 100\rangle$ edges, with the

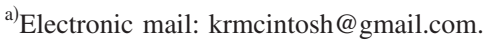

angle between the planes and the base being $54.75^{\circ}$ (Ref. 19). Rantex is formed by submitting $\{100\}$ wafers to a lowly concentrated alkaline solution buffered with isopropyl alcohol (IPA) and containing dissolved silicon at an elevated temperature, ${ }^{24}$ where the conditions are controlled to ensure the pyramids are between 1 and $10 \mu \mathrm{m}$ high: not so small

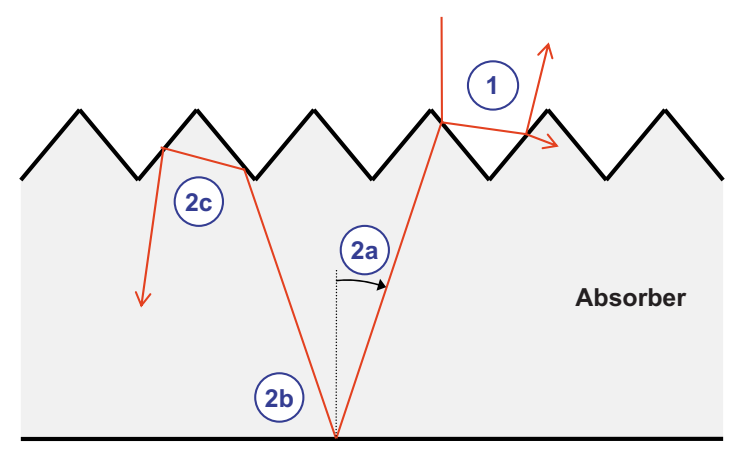

FIG. 1. (Color online) A textured front surface increases (1) transmission and (2) light trapping. (Refs. 1-5) Transmission increases when light is reflected from one facet onto a neighboring facet, and light trapping increases because the transmitted light has an angle to the perpendicular leading to (2a) a longer first pass through the absorber and usually (2b) a higher internal reflection at the rear surface. A textured front surface also tends to have (2c) a high internal reflection at the front surface. Note that when transmitted at an angle to the perpendicular, more light is absorbed near the front surface; this can be beneficial or deleterious depending on the location of the collecting $p-n$ junction and the relative rates of recombination within the cell. 


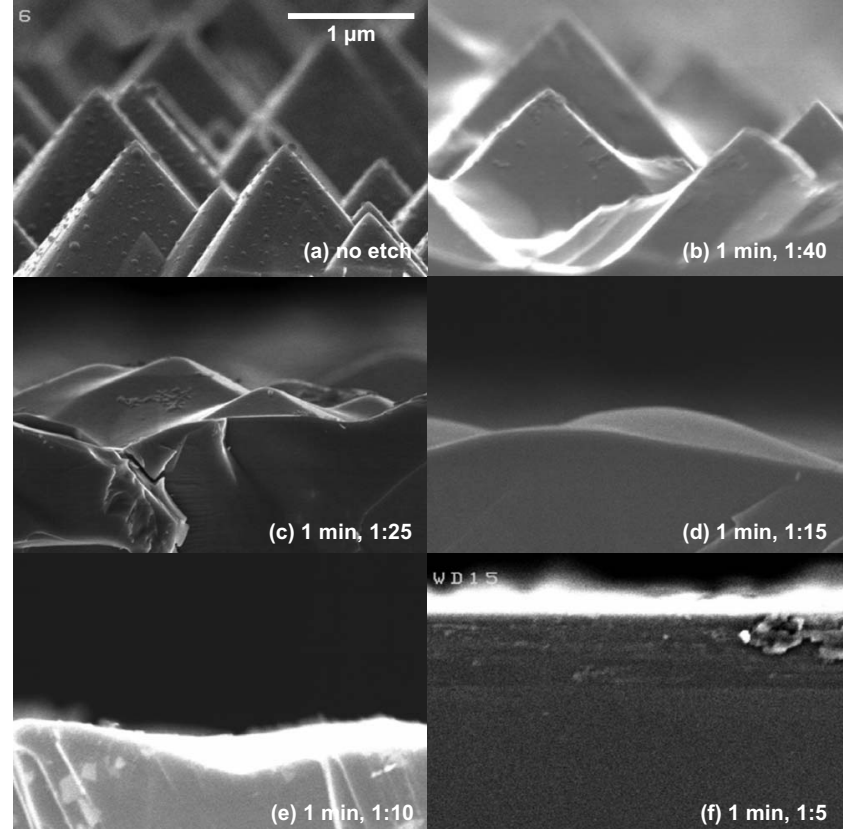

FIG. 2. SEM images of $\{100\}$ silicon wafers textured with random upright pyramids where the wafers were subsequently submitted to an $\mathrm{HF}: \mathrm{HNO}_{3}$ rounding etch at the time and concentration stated on each image.

that they introduce diffraction [becoming obsolete at $<10 \mathrm{~nm}$ (Ref. 25)], and not so large that they complicate subsequent fabrication steps by breaking ${ }^{26}$ or poking through resist. ${ }^{9}$ The procedure takes $10-60 \mathrm{~min}$ to cover the surface of a wafer with pyramids, ${ }^{14,16,17,20}$ where insufficient time or excessive alkaline concentration results in partially distributed pyramids (hillocks). ${ }^{17,19}$

The formation of rantex on $\{100\}$ silicon is relatively simple but superior morphologies have been attained using the same alkaline etchants. The inclusion of a patterned etchresist, such as $\mathrm{SiO}_{2}$, permits the formation of periodic inverted pyramids, upright pyramids, and perpendicular slats, all of which can exhibit better light trapping than rantex. ${ }^{4}$ The cost associated with patterning has prevented its application to one-sun commercial cells but it is applied to some laboratory cells. For example, the world's most efficient silicon solar cells under one-sun illumination incorporate periodic inverted pyramids. ${ }^{27,28}$ Interestingly, rantex can be optically improved by converting it into randomly distributed inverted pyramids ${ }^{8}$ but presumably the protective coating, partial polishing and additional etching required for the conversion is prohibitively expensive for commercial cells.

Alkaline etchants are also applied to multicrystalline silicon but the haphazard orientation of its crystals leads to greater reflection than from rantex. ${ }^{29,30}$ Multicrystalline silicon has also been textured with (i) bowls formed by vigorous acidic etching, ${ }^{31,32}$ (ii) bowls (or honeycomb) formed by the application of patterned resists and exposure to anisotropic etchants in liquid, ${ }^{28,33}$ plasma, ${ }^{34}$ or combined ${ }^{35}$ phases, and (iii) $\mathrm{V}$ grooves formed by mechanical means. ${ }^{36}$

The optical benefit provided by texture is partially mitigated by the additional recombination it invokes. Higher surface recombination arises from an increase in surface area and an exposure of crystal orientations with high defect den-

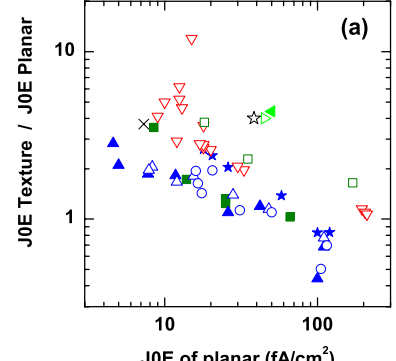

(a)

$\mathrm{JOE}$ of planar $\left(\mathrm{fA} / \mathrm{cm}^{2}\right)$

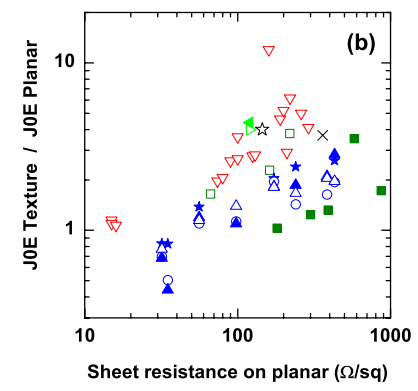

LEGEND

Jin: 12 um inv. pyr., $50 \mathrm{~nm} \mathrm{SiO}+$ + FGA

Schulz: 10 um bowls, $105 \mathrm{~nm} \mathrm{SiO}$

This work: 1.5 um rantex, $110 \mathrm{~nm} \mathrm{SiO}_{2}+\mathrm{FGA}$

King: rantex, $\mathrm{SiO}_{2}+\mathrm{FGA}$

King: rantex, $\mathrm{SiO}_{2}$ + alneal

Kerr: 10 um rantex, $13 \mathrm{~nm} \mathrm{SiO}_{2}$

Kerr: 10 um rantex, $13 \mathrm{~nm} \mathrm{\textrm {SiO } _ { 2 }}+\mathrm{FGA}$

- Kerr: 10 um rantex, $13 \mathrm{~nm} \mathrm{\textrm {SiO } _ { 2 }}$ + Alneal

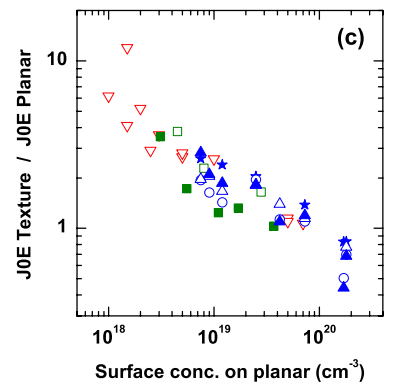

Glunz: inv. pyr., $\mathrm{SiO}_{2}+\mathrm{FGA}$

Schulz: 10 um bolws, $15 \mathrm{~nm} \mathrm{SiO}, 60 \mathrm{~nm}$ SiN

King: rantex, $\mathrm{SiO}_{2}+\mathrm{FGA}$

$\star$ Kerr: 10 um rantex, $\mathrm{SiN}$

FIG. 3. (Color online) The ratio of $J_{0 E}$ for textured and planar $\{100\}$ wafers submitted to the same phosphorus diffusion and passivation step, plotted as a function of (a) $J_{0 E}$, (b) diffusion sheet resistance, and (c) surface doping of the planar wafer (when available). The data is taken from King et al., (Ref. 41) Glunz et al.,(Ref. 38) Kerr et al., (Ref. 42) Schultz et al., (Ref. 35) Jin et al., (Ref. 43) and this work, where the sheet resistance of King et al. (Ref. 41) was calculated from the surface concentration and junction depth assuming an ERFC diffusion profile. The legend lists and the available detail regarding the texture and passivation.

sities. In the case of rantex, the surface area is 1.73 times greater than a planar sample and the exposed planes have a $\{111\}$ orientation-well known for its high density of dangling bonds. ${ }^{37}$ Recombination associated with textured surfaces can also differ from that associated with equivalently processed planar wafers due to the effect of texture on diffusion profiles, ${ }^{38}$ oxide growth, ${ }^{39}$ and possibly film stress in overlying films. ${ }^{39}$

This paper first reviews recombination studies on textured surfaces. The experimental data suggests that for light diffusions, the recombination at a textured surface might be greater than expected after considering the increase in surface area and the exposed $\{111\}$ planes. For very heavy diffusions, the recombination rate is similar whether the diffusion is performed on planar or textured surfaces. We then present capacitance-voltage experiments on rantex to quantify its density of interface states in comparison to equivalently prepared planar samples. A preliminary analysis of the $C V$ curves appeared in Ref. 40.

\section{RECOMBINATION AT TEXTURED SURFACES}

Recombination at a textured surface is generally larger than recombination at an equivalent planar $\{100\}$ surface. The relative increase is sometimes proportional to the relative change in surface area but it can be both higher and lower. ${ }^{10,35,38,41-46}$ When higher, the exposure of $\{111\}$ rather than $\{100\}$ planes ${ }^{42-45,47}$ and stress-induced defects ${ }^{45}$ have been attributed as potential causes. A re-examination of this experimental data-plotted in Figs. 3, 4, and 6-reveals several reasons for the vagaries. 


\section{A. Photoconductance measurements on phosphorus- diffused silicon}

Figure 3 examines recombination associated with phosphorus-diffused textured and planar surfaces. These are the most common experiments because the front surface of solar cells is almost always diffused with phosphorus. The $y$-axes in Fig. 3 plot the ratio between the emitter saturation current density $J_{0 E}$ of textured and planar $\{100\}$ surfaces when submitted to the same phosphorus diffusion and passivation steps; the ratio is plotted as a function of (a) $J_{0 E}$ of the planar surface, (b) sheet resistance of the phosphorus diffusion, and when available (c) surface concentration of the phosphorus diffusion, where all $x$-axes correspond to measurements on the planar samples.

Data is presented for a variety of passivating schemes as listed in the figure's legend. The passivation layer on some samples is a thermal silicon oxide $\left(\mathrm{SiO}_{2}\right)$ that is either unhydrogenated or hydrogenated by a forming-gas anneal (FGA) or an "alneal" (an FGA through a sacrificial layer of aluminum); hydrogenated oxides such as these are incorporated into high-efficiency solar cells. The passivation layer on other samples is amorphous silicon nitride $\left(\mathrm{SiN}_{x}\right)$ deposited by plasma-enhanced chemical vapor deposition (PECVD) similar to that applied in most commercial silicon solar cells. ${ }^{48}$

The textured samples of Fig. 3 have a morphology that is either rantex, ${ }^{41,42}$ periodic inverted pyramids, ${ }^{38,43}$ or deep bowls formed by plasma and $\mathrm{HF}: \mathrm{HNO}_{3}$ etching. ${ }^{35}$ The surface area of the pyramidal texture is 1.73 times the equivalent planar area, whereas the surface area of the deep bowls is $\sim 4$ times the equivalent planar area. ${ }^{35}$ Thus, if the increase in recombination invoked by the textured surfaces related solely to the increase in surface area, all data points would lie at a $J_{0 E}$ ratio of 1.73 for the pyramidal texture and $\sim 4$ for the deep-bowl texture, being independent of the $x$-axis. Instead, the $J_{0 E}$ ratio of a given passivation layer decreases from 2-12 for very light diffusions to below unity for heavy diffusions.

This trend can be understood by considering the recombination rates that occur at the surface and in the diffusion itself. ${ }^{47}$ A light phosphorus diffusion has a small $J_{0 E}$ when well passivated because Shockley-Read-Hall (SRH) recombination at the surface and Auger recombination in the diffusion are both low. As a diffusion becomes heavier, its $J_{0 E}$ rises because SRH recombination increases with surface doping and, more importantly, Auger recombination in the diffusion increases even faster (both enhanced by band-gap narrowing). Thus, as a diffusion becomes heavier, (i) its $J_{0 E}$ increases, and (ii) the relative contribution of SRH recombination at the surface decreases, making the samples less dependent on surface defects.

Thus, the high $J_{0 E}$ ratio of the lightly diffused sampleswhich is one to seven times greater than the area ratiosuggests the textured samples contain more surface defects than the $\{100\}$ planar samples. The higher defect density has been attributed to the texture having $\{111\}$ surfaces $^{43-45,47}$ whose density of dangling bonds is larger than at an equivalently passivated $\{100\}$ surface. ${ }^{37}$ This is consistent with the findings of Jin et al. ${ }^{43,49,50}$ who measured the $J_{0 E}$ of planar

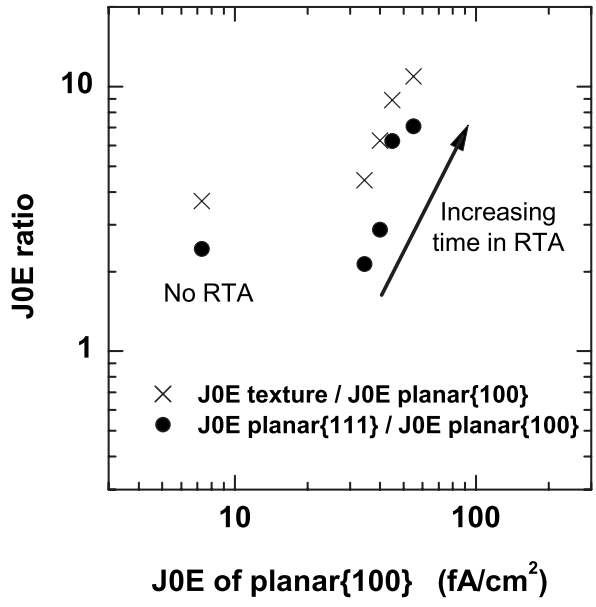

FIG. 4. $J_{0 E}$ ratio of oxide-passivated, phosphorus-diffused silicon after exposure to a rapid thermal anneal (RTA) at $550{ }^{\circ} \mathrm{C}$ in $\mathrm{N}_{2}$ for $0,0.5,1,3$, and 6 min. (Ref. 43)

$\{111\}$ silicon to be two to six times higher than the $J_{0 E}$ of planar $\{100\}$ silicon, where both were oxide-passivated, hydrogenated, and lightly diffused with phosphorus at $360-400 \Omega /$ sq. (Ratios of 10-20 occurred for the same structures when the $\mathrm{Si}-\mathrm{SiO}_{2}$ interface was unhydrogenated.)

On closer inspection, pyramidal texture might invoke a higher $J_{0 E}$ ratio than expected after accounting for the increase in surface area and the $\{111\}$ defect density. Figure 4 presents data from Jin et al. ${ }^{43}$ replotted as the $J_{0 E}$ ratio of both inverted pyramids and planar $\{111\}$ to planar $\{100\}$, where all samples were simultaneously diffused with a light phosphorus diffusion (360 $\Omega /$ sq on planar), oxidized with $50 \mathrm{~nm}$ of $\mathrm{SiO}_{2}$, and annealed in forming gas. Some samples were then submitted to a rapid thermal anneal (RTA) in $\mathrm{N}_{2}$ at $550{ }^{\circ} \mathrm{C}$ to remove hydrogen from the interface over increasing periods. The figure shows that as hydrogen is removed from the $\mathrm{Si}-\mathrm{SiO}_{2}$ interface, both $J_{0 E}$ ratios increase sharply due to the higher number of dangling bonds in $\{111\}$ than $\{100\} ;{ }^{37}$ this indicates that the $J_{0 E}$ of rantex is strongly dependent on hydrogen concentration in the same manner as planar $\{111\}$. The figure also shows that regardless of the RTA, the $J_{0 E}$ of texture remains $1.8 \pm 0.4$ higher than the planar $\{111\}$; while this ratio is consistent with the ideal area ratio of 1.73, the samples in this study had significant flat regions between the inverted pyramids, making their area ratio less than ideal. Thus, Jin et $a l^{45}$ concluded that texture may induce more defects than expected after considering the surface area and crystal orientation. Three possible reasons for this relate to the texture causing (i) stress in overlying films that induces additional interface defects, ${ }^{39}$ (ii) a spatially nonuniform diffusion profile, ${ }^{38}$ and (iii) a difference in charge density within overlying films.

As mentioned above, Auger recombination increases more rapidly with doping than SRH recombination at the surface, thereby mitigating the impact of surface defects and surface charge on the $J_{0 E}$. In Fig. 3, this effect is evidenced by the decrease in $J_{0 E}$ ratio as the phosphorus diffusion becomes heavier. In fact, the $J_{0 E}$ ratio declines below the surface area ratio, presumably because the deeper regions of the diffusion do not conform to the surface texture, as illustrated 


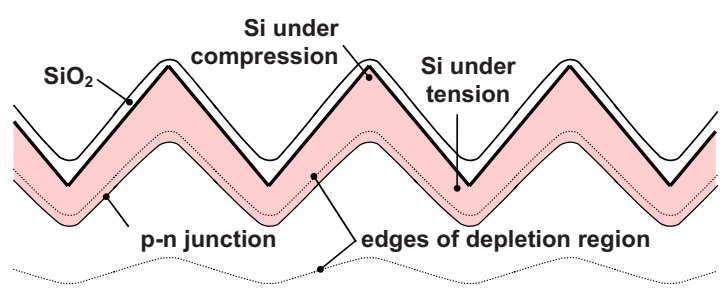

FIG. 5. (Color online) A diffused and oxidized rantex surface illustrating how the diffusion and its associated depletion region might not conform to the textured surface. The figure also shows the location of stress and how the oxide grows nonuniformly. (Ref. 39)

by Fig. 5 . If so, the reduction in the $J_{0 E}$ ratio would be more rapid for texture of smaller feature size-an attribute that is not always recorded.

Interestingly, the $J_{0 E}$ ratio in Fig. 3 declines below unity, suggesting that less recombination occurs at a textured surface than at a planar surface of the same heavy diffusion. This misleading trait can be understood by remembering that the $J_{0 E}$ ratio is plotted for pairs of wafers submitted to the same diffusion conditions-but which do not necessarily have the same diffusion profile-and that the $x$-axes on all graphs correspond to planar samples. Kerr et al. ${ }^{42}$ show that when submitted to the same heavy phosphorus diffusion, the sheet resistance of a textured sample is larger than that of a planar sample. Their data is replotted in Fig. 6 as a function of sheet resistance (assuming a linear interpolation of $J_{0 E}$ with the sheet resistance of the planar samples), indicating that the $J_{0 E}$ ratio falls below the surface area ratio but not below unity. In Fig. 3, therefore, the decline of the $J_{0 E}$ ratio below unity occurs because the same heavy diffusion leads to a heavier dopant profile in the planar than the textured wafers.

As discussed by many, $5,38,39,42,51$ experiments that compare texture to planar are hampered by differing dopant profiles and spatial nonuniformity when submitted to the same diffusion conditions. Complicating matters further, Cousins and Cotter $^{39}$ report that stacking faults can be introduced into the bulk of a wafer-and presumably into the interface and diffusion-by the growth of a thick oxide on rantex. The

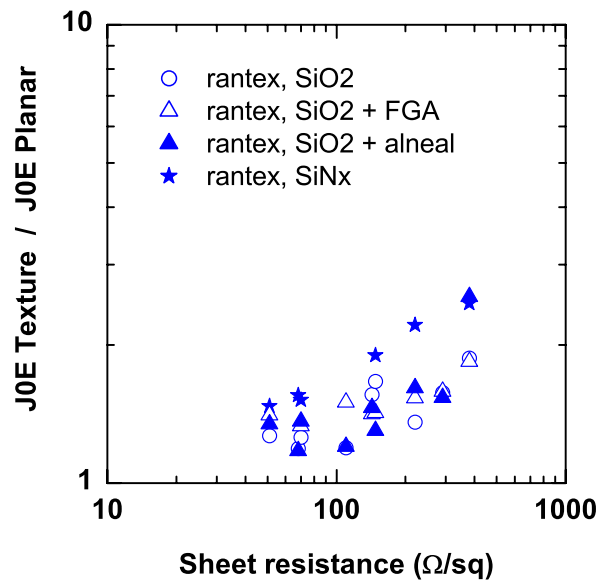

FIG. 6. (Color online) Data of Kerr et al. (Ref. 42) from Fig. 3(b) replotted such that the $J_{0 E}$ ratio refers to samples of equivalent sheet resistance rather than diffusion conditions. defects are generated during oxidation due to the introduction of stress in the silicon (tensile in the valleys and compressive at the peaks ${ }^{52}$ ), which is lessened for thinner $\mathrm{SiO}_{2}$ or when grown in the presence of $-\mathrm{OH}$ or $\mathrm{P}_{2} \mathrm{O}_{5}$. We omit their results from Fig. 3, however, because the related photoconductance lifetime measurements are affected by asymmetrical capture cross-sections associated with the stacking-fault defect, complicating the extraction of $J_{0 E}$.

Finally, we note that the lowest $J_{0 E}$ measured on phosphorus-diffused rantex is $8 \mathrm{fA} / \mathrm{cm}^{2}{ }^{53}$ The phosphorus diffusion was $140 \Omega / \mathrm{sq}$ and passivated with an $\mathrm{SiO}_{2} / \mathrm{SiN}_{x}$ stack, where the $\mathrm{SiO}_{2}$ was $40 \mathrm{~nm}$ and grown by a dry thermal oxidation at $1050{ }^{\circ} \mathrm{C}$, and the $\mathrm{SiN}_{x}$ was $40-70 \mathrm{~nm}$ and deposited by chemical vapor using an expanding thermal plasma. The $J_{0 E}$ was $\sim 50 \mathrm{fA} / \mathrm{cm}^{2}$ after thermal oxidation (no hydrogenation), $\sim 20 \mathrm{fA} / \mathrm{cm}^{2}$ after $\mathrm{SiN}_{x}$ deposition and $8 \mathrm{fA} / \mathrm{cm}^{2}$ after firing for $\mathrm{SiN}_{x}$ films of high refractive index. We add, however, that the lifetime graphs exhibit an injection dependence, possibly due to the interface charge density, which introduces some uncertainty into their $J_{O E}$.

\section{B. Photoconductance measurements on nondiffused silicon}

In addition to phosphorus-diffused silicon, experimental comparisons between rantex and planar silicon have been conducted on nondiffused silicon. When passivated with 110 $\mathrm{nm}$ of hydrogenated dry $\mathrm{SiO}_{2}$, Lauinger et al. ${ }^{10}$ found the ratio of surface recombination on rantex to planar $\{100\}$ to be 2.8 and 3.8 on 1.5 and $0.7 \Omega \mathrm{cm}$-type silicon, respectively, at an excess carrier density of $10^{14} \mathrm{~cm}^{-3}$. These results are consistent with those of phosphorus-diffused silicon, where the $J_{0 E}$ ratio exceeds that which is expected due to the larger surface area.

When passivated with PECVD $\operatorname{SiN}_{x}$, Lauinger et al. ${ }^{10}$ found the recombination ratio of rantex/planar to be 5 and 1.8 on the same 1.5 and $0.7 \Omega \mathrm{cm} p$-type silicon (at $10^{15} \mathrm{~cm}^{-3}$ ), while Chen et al. ${ }^{45,46}$ found the ratio to vary from $\sim 1.5$ to 35 on $1 \Omega \mathrm{cm} p$-type silicon depending on the deposition and annealing conditions. The high variation associated with the $\mathrm{SiN}_{x}$ may be due to small changes in its fixed charge, a property that has a strong affect on recombination at nondiffused surfaces, ${ }^{54}$ and to differing hydrogenation at the $\mathrm{Si}-\mathrm{SiO}_{2}$ interface.

Jin et al. $^{44}$ provide the most detailed study on nondiffused oxide-passivated silicon, comparing the surface recombination velocity (SRV) of planar $\{100\}$ and invertedpyramid samples, where all were $p$-type with a nominal resistivity $>100 \Omega \mathrm{cm}$ and coated with $50 \mathrm{~nm}$ of thermal $\mathrm{SiO}_{2}$. When the $\mathrm{Si}-\mathrm{SiO}_{2}$ interfaces were hydrogenated, they found recombination associated with the inverted pyramids to be two to four times larger than with the planar $\{100\}$ surface, consistent with the results of Lauinger et al. ${ }^{10}$ When dehydrogenated, the recombination ratio increased to $\sim 11$, suggesting a greater influence of the dangling-bond interface states, consistent with their results on diffused silicon ${ }^{43}$ (Fig. 4) and with the electron spin resonance experiments of Stesmans and Afanas'ev. ${ }^{37}$ We treat these results with caution, however, because they did not account for a nonlinear response of the lifetime instrument that has since been found to 
affect samples of low conductance, ${ }^{55}$ and therefore underestimated the absolute SRV. We also note that a direct comparison of the planar $\{111\}$ wafers in the same experiment is compromised by them being $n$-type, since any fixed positive charge in the $\mathrm{SiO}_{2}$ would increase SRV at a $p$-type surface but decrease SRV at an $n$-type surface (perhaps evidenced by the similar SRV attained in $\{100\}$ and $\{111\}$ hydrogenated samples).

\section{Capacitance-voltage experiments on textured silicon}

Recart and Cuevas ${ }^{51}$ measured and simulated the quasisteady state capacitance of $p$-type cells textured with rantex and diffused with phosphorus. They showed that the $p-n$ junction capacitance depends on pyramid size, emitter doping, bulk doping, and voltage-a consequence of the capacitance being dependent on the area of the space-charge region on the $p$-type bulk side of the junction (see Fig. 5). Thus, for lightly doped cells, the equivalent junction area was unity, and for heavily doped abrupt-junction cells, the equivalent junction area increased to 1.73 .

The only capacitance-voltage $(C V)$ studies we have found on nondiffused textured silicon are those by Sun et $a l .{ }^{17}$ and Papet et $a l^{21}$ The first study investigated $0.5-1.5 \Omega \mathrm{cm}$-type silicon textured with rantex and coated with an unspecified thickness of PECVD $\mathrm{SiN}_{x}$, finding the accumulation capacitance to be $1.76 \pm 0.06$ times greater than that of equivalent planar samples, consistent with the increase in surface area (1.73). The second study investigated 1-10 $\Omega \mathrm{cm} p$-type silicon textured with rantex and coated with $50 \mathrm{~nm}$ of thermal $\mathrm{SiO}_{2}$, finding the insulator charge to be more positive when the rantex was formed by $\mathrm{KOH}$ rather than TMAH, possibly due to mobile $\mathrm{K}^{+}$impurities or to more interface defects. Neither studies analyzed the $C V$ curves to evaluate interface states.

\section{Summary}

Investigations of recombination at textured surfaces have several consistent features: when textured silicon is either lightly diffused or nondiffused, the recombination is significantly greater than at equivalent planar $\{100\}$ silicon. The higher recombination arises from SRH recombination at the surface being greater because (i) the surface area is larger, (ii) the surface defect density is higher due to the exposure of $\{111\}$ rather than $\{100\}$ planes, and possibly (iii) the surface defect density is still higher due to other reasons such as stress induced during oxide growth. The SRH recombination at textured surfaces is also more strongly dependent on hydrogen passivation due to its surfaces having a $\{111\}$ orientation, and therefore have a higher density of dangling bonds than $\{100\}$. When textured silicon is very heavily diffused, recombination approaches that which occurs on planar silicon because (i) the diffusion profile is deep, making the surface area less relevant, and (ii) Auger recombination dominates, making surface defects inconsequential.

We now present an experiment that employs photoconductance and capacitance-voltage measurements to investi-

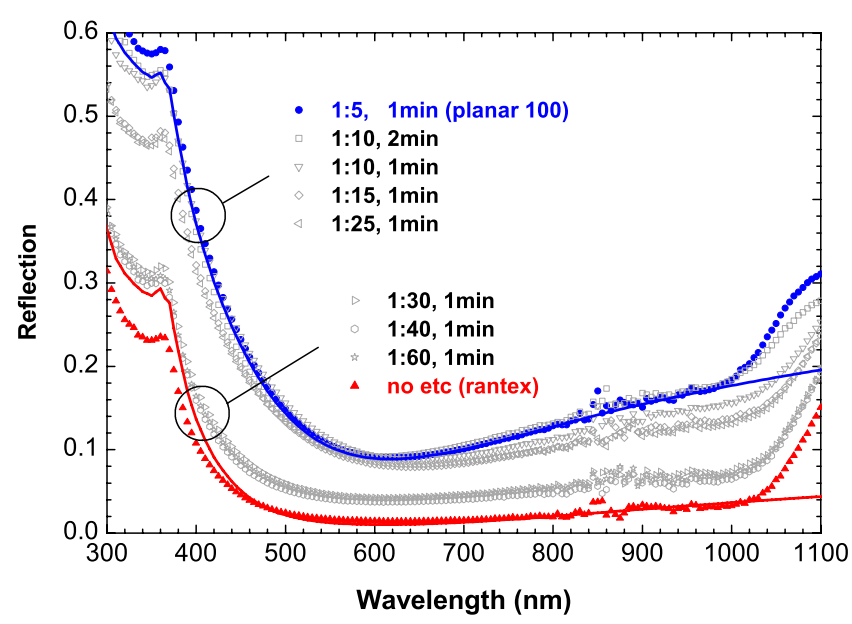

FIG. 7. (Color online) Hemispherical reflection of $\mathrm{SiO}_{2}$-coated rantex silicon after a rounding etch at various concentrations of $\mathrm{HF}: \mathrm{HNO}_{3}$ (symbols) and calculated reflection for $110 \mathrm{~nm}$ of $\mathrm{SiO}_{2}$ on rantex and $101 \mathrm{~nm}$ of $\mathrm{SiO}_{2}$ on planar (lines) for light normally incident to the plane of the wafer.

gate recombination at silicon textured with rantex and passivated with $\mathrm{SiO}_{2}$, and more specifically, the defect density at the $\mathrm{Si}-\mathrm{SiO}_{2}$ interface.

\section{SAMPLE PREPARATION}

The samples prepared for $C V$ measurements were fabricated from $\{100\}$ float-zoned $p$-type silicon wafers with a nominal resistivity of $8-12 \Omega \mathrm{cm}$, a thickness of $500 \mu \mathrm{m}$, and a diameter of $100 \mathrm{~mm}$. The wafers were first etched in 1:5 $\mathrm{HF}: \mathrm{HNO}_{3}$ for $3 \mathrm{~min}$ at room temperature to remove residual surface damage, then textured in an alkaline solution of 3.6\% TMAH and 12\% IPA with dissolved silicon for 45 min at $80{ }^{\circ} \mathrm{C}$ to create rantex with a pyramid height of $\sim 1.5 \mu \mathrm{m}$. The textured wafers were divided into quarters and submitted to a variety of $\mathrm{HF}: \mathrm{HNO}_{3}$ solutions for either 1 or 2 min to "round" the pyramids, the purpose of which will become apparent in Sec. IV. Figure 2 presents SEM images of the resulting morphology where the concentration of the $\mathrm{HF}: \mathrm{HNO}_{3}$ solutions and the etch time is recorded on each image. The figure includes (a) rantex that did not receive a "rounding etch," (b)-(e) rantex that received an increasingly concentrated rounding etch, and (f) a sample that received a sufficiently concentrated rounding etch to convert rantex to planar $\{100\}$ in $1 \mathrm{~min}$. Consistent with the observations of Cousins and Cotter, ${ }^{39}$ the weaker solutions round the troughs rather than the peaks of the pyramids. (Note that all $\mathrm{HF}: \mathrm{HNO}_{3}$ ratios quoted in this work refer to the ratio of a $50 \% \mathrm{HF}$ solution and a $70 \% \mathrm{HNO}_{3}$ solution, where both are diluted in $\mathrm{H}_{2} \mathrm{O}$; hence, 1:5 $\mathrm{HF}: \mathrm{HNO}_{3}$ is actually 1:7:4 $\mathrm{HF}: \mathrm{HNO}_{3}: \mathrm{H}_{2} \mathrm{O}$.)

Following the $\mathrm{HF}: \mathrm{HNO}_{3}$ rounding etch, the samples were RCA cleaned and oxidized. The $\mathrm{SiO}_{2}$ was grown in dry $\mathrm{O}_{2}$ at $1100{ }^{\circ} \mathrm{C}$ for $30 \mathrm{~min}$ and then annealed in $\mathrm{N}_{2}$ at $1100{ }^{\circ} \mathrm{C}$ for $30 \mathrm{~min}$ and $\mathrm{FG}$ at $400{ }^{\circ} \mathrm{C}$ for $30 \mathrm{~min}$. Since the samples were unpolished, the $\mathrm{SiO}_{2}$ thickness could not be assessed by ellipsometry; it could, however, be determined from hemispherical reflection measurements. Figure 7 plots this reflection, showing a significant increase as the samples are transformed from rantex to planar, including a sudden 
increase in reflection for solutions of concentration, 1:25, and above. Presumably, rays incident to the low-reflection samples are predominantly reflected onto neighboring facets, while rays incident to the high-reflection samples are not. The relevance of the reflection to silicon solar cells is quantified in Fig. 8(a), which plots the solar-weighted reflectance (SWR) calculated from the AM1-5g spectrum, ${ }^{56}$ integrated over the range $300-1100 \mathrm{~nm}$ and converted to an equivalent photon current. The SWR of these oxide-coated samples increases from $3.2 \%$ for rantex to $15.7 \%$ for planar.

The $\mathrm{SiO}_{2}$ thickness of the rantex and planar samples was determined by fitting a calculated reflectance to the experimental reflectance, where the former is determined by the transfer matrix method for thin-film optics ${ }^{57}$ using the refractive index of $\mathrm{SiO}_{2}$ and $\mathrm{Si}$ in Refs. 58 and 59. In the case of rantex, it was assumed that all incident rays were incident at $54.75^{\circ}$ to the first facet and $15.75^{\circ}$ to the neighboring facet (additional intersections neglected), as determined from a geometrical consideration of normally incident light. The $\mathrm{SiO}_{2}$ thickness that gave the best fit between calculated and experimental data was $110 \mathrm{~nm}$ for rantex and $101 \mathrm{~nm}$ for planar. A slightly thicker oxide is expected on $\{111\}$ compared to $\{100\}$ surfaces. ${ }^{60}$ Figure $8(\mathrm{~b})$ plots the estimated oxide thickness on these and intermediate samples prior to HF fuming.

The $C V$ measurement required the subsequent formation of metal oxide semiconductor (MOS) structures. Here, the front metal contact was formed by the evaporation of 7-8 nm of aluminum through a shadow mask to create circular contacts of diameter $785 \pm 10 \mu \mathrm{m}$. The rear contact was formed by removing the $\mathrm{SiO}_{2}$ with $\mathrm{HF}$ vapor and coating the surface with a GaIn eutectic paste. The $\mathrm{HF}$ vapor removed all $\mathrm{SiO}_{2}$ from the rear of the samples, as required, but it also removed $25 \pm 5 \mathrm{~nm}$ from the front surface. Figure 8(b) plots the estimated $\mathrm{SiO}_{2}$ thickness of the completed MOS structures after HF fuming.

The samples prepared for photoconductance measurements were fabricated by a similar procedure. The starting material was $\{100\}$ float-zoned $n$-type silicon wafers with a nominal resistivity of $>100 \Omega \mathrm{cm}$, a thickness of $400 \mu \mathrm{m}$, and a diameter of $100 \mathrm{~mm}$. The wafers received the same $\mathrm{HF}: \mathrm{HNO}_{3}$ etch, texturing, quartering, rounding etch, RCA clean, and oxidation that was applied to the $C V$ samples, but between the RCA clean and oxidation, they received a light $\mathrm{POCl}_{3}$ diffusion with a postprocessing sheet resistance of $130-160 \Omega$ /sq. This phosphorus diffusion is similar to that given to high-efficiency solar cells to further passivate the surface. Being symmetrically diffused with a lightly doped substrate, the samples permitted an accurate assessment of their high-injection bulk lifetime and emitter saturation current density via transient PC analysis. ${ }^{61}$

\section{CV RESULTS}

Quasistatic and high-frequency $C V$ measurements were attempted on ten MOS structures on each sample. On many occasions, the $\mathrm{SiO}_{2}$ was too leaky to take a meaningful quasistatic $C V$ curve, particularly for the more textured samples. In fact, no structures could be measured on the rantex sample that was not submitted to a rounding etch. Figure 8(c) plots

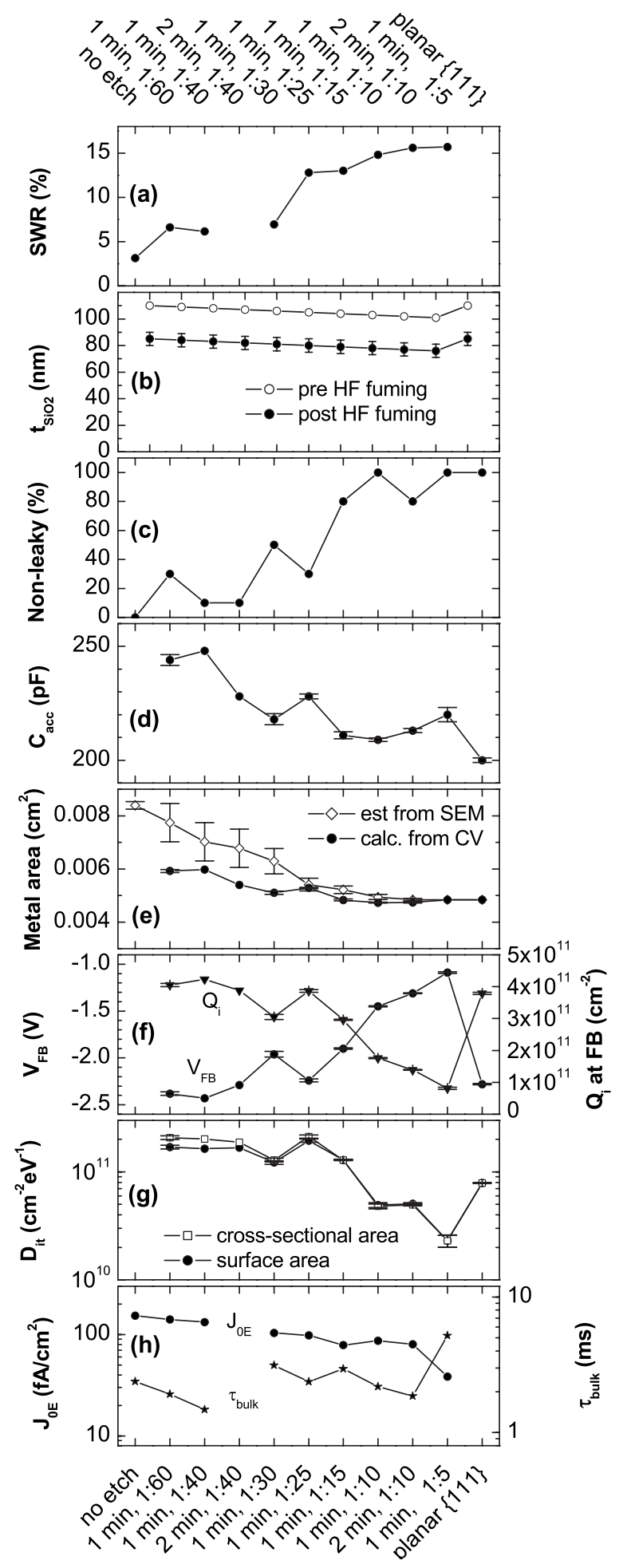

FIG. 8. (a) SWR, (b) oxide thickness, (c) fraction of nonleaky MOS structures, (d) accumulation capacitance $C_{\mathrm{acc}}$, (e) metal area, (f) flat-band voltage $V_{\mathrm{FB}}$ and equivalent insulator charge located at the $\mathrm{Si}-\mathrm{SiO}_{2}$ interface $Q_{i},(\mathrm{~g})$ density of interface states $D_{\text {it }}$ at midgap, and (h) emitter saturation current density $J_{0 E}$ and high-injection bulk lifetime $\tau_{\text {bulk }}$, where all parameters are measured on MOS structures created on rantex that has been etched in $\mathrm{HF}: \mathrm{HNO}_{3}$ for the times and concentrations listed in the figure. The various etches lead to a gradual change from rantex (no etch) to planar $\{100\}$ (1 min, 1:5). For comparison, results of planar $\{111\}$ silicon are also presented. Error bars associated with the $C V$ experiments represent the standard deviation from the mean of the nonleaky MOS measurements.

the fraction of measured diodes for each sample, indicating that the prohibitively leaky diodes occur less frequently on more planar morphologies. 

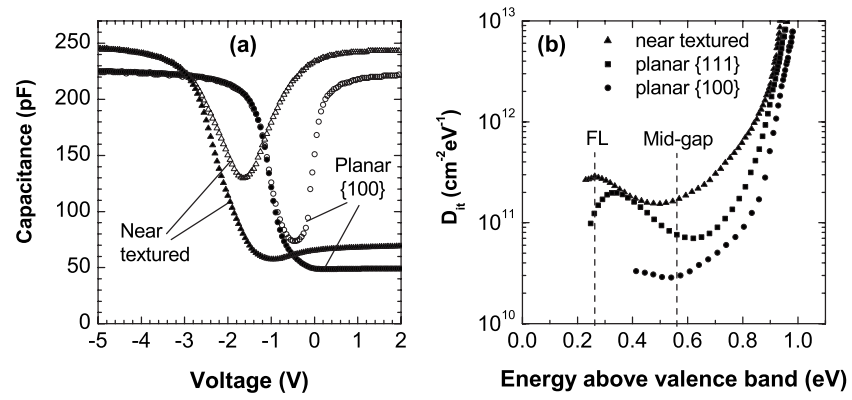

FIG. 9. (a) High frequency (solid symbols) and quasistatic (open symbols) $C V$ data, and (b) the density of interface states $D_{\text {it }}$ calculated by a Castagne analysis as a function of energy $E$, where the data was measured from MOS structures fabricated on planar $\{100\}\left(1 \mathrm{~min}, 1: 5 \mathrm{HF}: \mathrm{HNO}_{3}\right)$ and neartextured $\left(1 \mathrm{~min}, 1: 60 \mathrm{HF}: \mathrm{HNO}_{3}\right)$ silicon. For comparison, $D_{\mathrm{it}}(E)$ is also plotted for a representative planar $\{111\}$ sample. In the case of the neartextured sample, $D_{\mathrm{it}}(E)$ corresponds to the effective surface area determined from $C_{\text {acc }}$

Figure 9(a) plots the $C V$ curves of a representative sample that received a weak rounding etch (1:60) leaving it "near-textured," and of another that received a sufficiently strong etch (1:5) to render it planar $\{100\}$. Several features of these curves are now discussed.

First, the accumulation capacitance $C_{\text {acc }}$ is higher for the near-textured sample. This is due primarily to the sample's larger surface area, as indicated by Fig. 8(d), which shows $C_{\text {acc }}$ becoming progressively smaller as the texture is transformed from rantex to planar. In Fig. 8(e), the surface area $A$ is calculated from $C_{\text {acc }}$ by the equation ${ }^{62}$

$$
C_{\mathrm{acc}}=\frac{\varepsilon_{\mathrm{SiO}_{2}}}{t_{\mathrm{SiO}_{2}}} A,
$$

where $\varepsilon_{\mathrm{SiO}}$ is the permittivity of the $\mathrm{SiO}_{2}$ assumed to be $3.9 \varepsilon_{0} \mathrm{~F} / \mathrm{cm}^{2},{ }^{63}$ and $t_{\mathrm{SiO}}$ is the thickness of the $\mathrm{SiO}_{2}$ taken from Fig. 8(b) after HF fuming. This calculated surface area is plotted in Fig. 8(e) and compared to the surface area estimated from the diameter of the metal contact and the morphology observed in SEM images. The difference between these areas is significant for the more textured samples, probably due to charge being nonuniformly distributed over their surface. Such nonuniformity compromises the $C V$ analysis that follows and hence the results are treated with caution.

A second feature of Fig. 9(a) is the turning point in the high-frequency curve of the near-textured sample but not the planar sample. This indicates that the frequency is insufficient to prevent some interface states at the near-textured surface from responding to the ac signal. Such turning points occurred in all but the most rounded-i.e., planar $\{100\}$ samples, which had the fewest interface states. In these samples, the bulk doping could be determined from the inversion capacitance; ${ }^{62}$ it was calculated to be $1.25 \pm 0.25$ $\times 10^{15} \mathrm{~cm}^{-3}$, equivalent to $11 \pm 2 \Omega \mathrm{cm}$ and consistent with the nominal resistivity quoted by the wafer supplier (8-12 $\Omega$ cm p-type).

A third feature of Fig. 9(a) is the difference in flat-band voltage $V_{\mathrm{FB}}$ between $C V$ curves. $V_{\mathrm{FB}}$ of the near-textured samples is more negative, indicating that there is either more positive charge in the $\mathrm{SiO}_{2}$ or that there is a higher density of

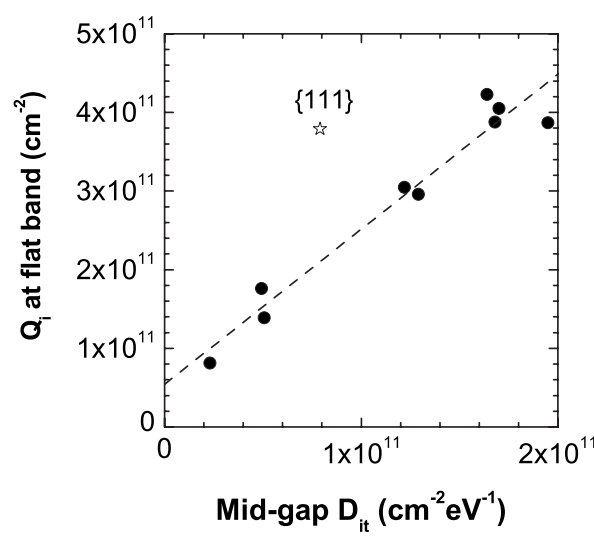

FIG. 10. Insulator charge density $Q_{i}$ as a function of the midgap $D_{\mathrm{it}}$, where $Q_{i}$ is determined at flat band from $V_{\mathrm{FB}}$ and the work function difference between the aluminum and silicon assuming all charge is located at the $\mathrm{Si}-\mathrm{SiO}_{2}$ interface. Both axes refer to a surface-area density.

positive interface states (i.e., unoccupied donorlike defects) at the $\mathrm{Si}-\mathrm{SiO}_{2}$ interface under flat-band conditions. Figure 8(f) plots $V_{\mathrm{FB}}$ for each morphology, as well as the equivalent flat-band insulator charge density $Q_{i}$ calculated as if all charge occurred at the interface using the effective surface area determined from $C_{\mathrm{acc}}$. The figure shows that $V_{\mathrm{FB}}$ becomes less negative as the samples are transformed from rantex to planar $\{100\}$, equivalent to a decrease in $Q_{i}$ from +3.3 to $+0.6 \times 10^{11} \mathrm{~cm}^{-2}$. It is shown below that this change in charge density relates predominantly to a change in interface charge rather than a change in fixed $\mathrm{SiO}_{2}$ charge.

A fourth feature of Fig. 9(a) is the difference in "stretchout" between $C V$ curves. The near-textured sample exhibits significantly more "stretch-out," indicative of a higher density of interface states $D_{\text {it }}$. Figure 9(b) plots $D_{\text {it }}$ as a function of energy $E$ above the valence band determined by applying the Castagne and Vapaille's analysis ${ }^{64}$ to the curves of Fig. 9(a). $D_{\mathrm{it}}(E)$ is only plotted where reasonable accuracy is attained from the difference in quasi-static and high-frequency curves. At midgap, $D_{\text {it }}$ is almost ten times greater for the near-textured sample than for the planar $\{100\}$ sample.

Figure 9(b) also plots $D_{\mathrm{it}}(E)$ of a representative planar $\{111\}$ sample, which exhibits a similar peak to the nearrantex sample at $\sim 0.3 \mathrm{eV}$ above the valence band. This peak is consistent with the donorlike $P_{L}$ defect associated with dangling bonds with one oxygen back bond. ${ }^{65}$ At energies above this $P_{L}$ peak, $D_{\mathrm{it}}(E)$ of near-rantex exceeds that of planar $\{111\}$ and as reasoned below, these defects are likely to be acceptorlike. The accuracy of the experiment prevents examination of $D_{\mathrm{it}}(E)$ below the $P_{L}$ peak.

Figure $8(\mathrm{~g})$ plots $D_{\text {it }}$ at midgap for all morphologies. It is plotted in two ways. First, in terms of the surface area as determined from $C_{\text {acc }}$, but also in terms of the cross-sectional area of the MOS structure, which is more relevant to solar cells. The surface-area midgap $D_{\text {it }}$ of the near-textured samples is 2.0 times greater than that of the planar $\{111\}$ sample, and 7.5 times greater than that of the planar $\{100\}$ sample; in terms of cross-sectional area, the ratios are 2.5 and 8.9 , respectively.

The source of the charge density $Q_{i}$ can be understood with Fig. 10. It plots $Q_{i}$ against midgap $D_{\text {it }}$ and depicts a 


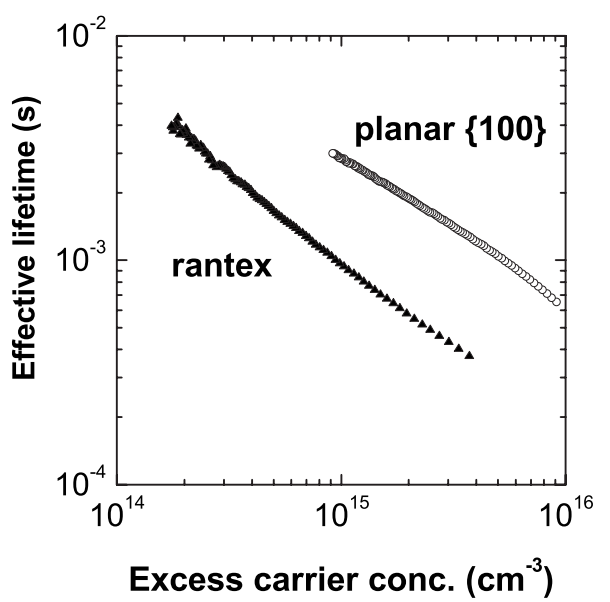

FIG. 11. Effective lifetime $\tau_{\text {eff }}$ as a function of excess carrier concentration of rantex and planar $\{100\}$ samples.

linear relationship. This indicates that the difference in $Q_{i}$ of one morphology to another is primarily due to changes in positive charge associated with interface states rather than changes in fixed oxide charge, and that the interface charge decreases as the orientation is converted from $\{111\}$ to $\{100\}$. Supporting this conclusion is the high $Q_{i}$ of the $\{111\}$ sample (discussed in more detail below). We deduce that the fixed oxide charge is similar for all samples and is given by the intercept of the linear fit; i.e., $Q_{i}$ if there were no interface charge. The intercept is $5.4 \times 10^{10} \mathrm{~cm}^{-2}$, consistent with the accepted value for a thermal oxide of between 5 and 20 $\times 10^{10} \mathrm{~cm}^{-2}{ }^{66}$

The higher positive charge of the planar $\{111\}$ and textured samples can be partially attributed to the donorlike $P_{L}$ defects. In these $p$-type samples, a significant fraction of the $P_{L}$ distribution is above the Fermi level, making such defects unoccupied under flat-band conditions and therefore positively charged. Interestingly, the near-rantex samples have a similar $Q_{i}$ but twice the interface states as the planar $\{111\}$ samples; this suggests that the additional defects associated with rantex are neutral and therefore either acceptorlike above the Fermi level (unoccupied) or donorlike below the Fermi level (occupied). Since there is a large difference in $D_{\mathrm{it}}(E)$ between the $\{111\}$ and near-textured samples above the Fermi level [Fig. 9(b)], we conclude that these defects are predominantly acceptorlike.

In summary, the $C V$ measurements indicate that under the oxidation and annealing conditions described above, rantex has $\sim 9$ times and planar $\{111\}$ has 3.6, times more midgap interface states than a $\{100\}$ surface. Furthermore, rantex exhibits more interface states than can be explained by its larger surface area and $\{111\}$ orientation, and these defects are predominantly acceptorlike defects above the $P_{L}$ distribution and donorlike below the $P_{L}$ distribution.

\section{PHOTOCONDUCTANCE RESULTS}

Figure 11 presents the results of photoconductance experiments, plotting the effective carrier lifetime $\tau_{\text {eff }}$ as a function of excess carrier concentration. The figure shows that at carrier densities relevant to solar cell operation, $\tau_{\text {eff }}$ of the rantex sample was substantially shorter than $\tau_{\text {eff }}$ of the planar

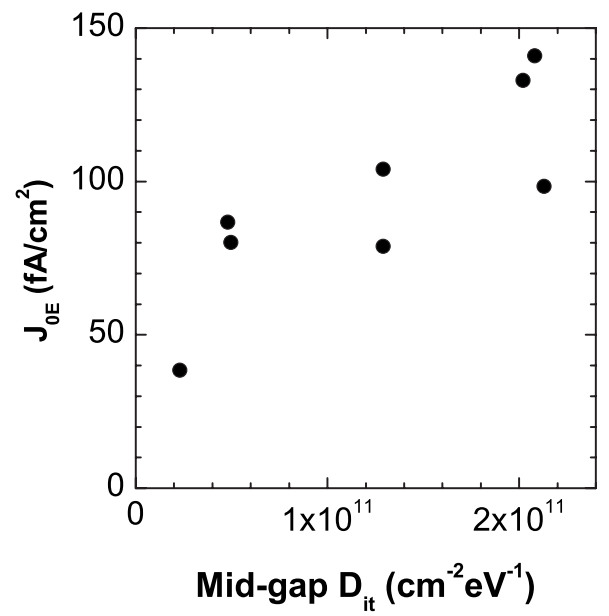

FIG. 12. Emitter saturation current density $J_{0 E}$ from the PC experiment plotted against the midgap $D_{\text {it }}$ from the $C V$ experiment for samples of the same morphology. Both axes refer to the cross-sectional area of the test structures.

$\{100\}$ sample. The data was analyzed to determine the samples' emitter saturation current density $J_{0 E}$ and bulk lifetime $\tau_{\text {bulk }}$, following the procedure devised by Kane and Swanson $^{61}$ but for vertically symmetric samples and with modern values for the intrinsic concentration and carrier mobility. The results are plotted in Fig. 8(h) for all morphologies, where the $J_{0 E}$ density corresponds to the cross-sectional area of the samples, as is also the case in Figs. 3, 4, and 6 .

Figure $8(\mathrm{~h})$ shows that $J_{0 E}$ decreases as the surface become more planar, consistent with the decrease in $D_{\mathrm{it}}$ found in Sec. IV. The $J_{0 E}$ of the rantex sample is four times greater than the $J_{0 E}$ of the planar $\{100\}$ sample, a ratio that is compared to similar studies in Fig. 3. The $J_{0 E}$ is plotted against the midgap $D_{\text {it }}$ (cross-sectional area) for the same morphology in Fig. 12.

After etching rantex in a weak $\mathrm{HF}: \mathrm{HNO}_{3}$ solution, Cousins and Cotter ${ }^{39}$ and Jin et al. ${ }^{43}$ also observed a decrease in $J_{0 E}$ of phosphorus-diffused test structures, and Chong ${ }^{67}$ observed a $5 \mathrm{mV}$ rise in the open-circuit voltage of buriedcontact solar cells. Unfortunately, even a weak rounding etch leads to considerably higher reflection, and like Cudzinovic and McIntosh, ${ }^{68}$ we conclude that it would cause a net decrease in a solar cell's efficiency.

Finally, Fig. 8(h) indicates that $\tau_{\text {bulk }}$ increases as the samples become less textured. This might relate to the textured samples incurring bulk defects during oxidation due to stress at the peaks and troughs of the pyramids, as concluded by Cousins and Cotter $^{39}$ for a much thicker $\mathrm{SiO}_{2}$.

\section{CONCLUSION}

A review of previous work uncovered the degree to which the recombination associated with textured silicon exceeds that of planar $\{100\}$ silicon. In samples where SRH recombination is small relative to Auger recombination, as when the surface is heavily diffused, the recombination of textured samples exceeds that of planar $\{100\}$ samples by about the same degree as the relative difference in surface area. In fact, for very heavily diffused samples, the relative 
change in recombination is less than the relative change in surface area, probably because the diffusion does not conform to the texture.

In samples where recombination occurs predominantly via the SRH mechanism at the surface, such as samples that are nondiffused or lightly diffused with phosphorus, textured surfaces exhibit 2-12 times more recombination. The additional recombination is due to (i) a larger surface area, which is 1.73 for ideal pyramidal texture; (ii) a higher fraction of dangling bonds when non- $\{100\}$ surfaces are exposed, such as the $\{111\}$ surfaces of pyramidal texture; and possibly (iii) additional defects induced by film stress. When oxidepassivated, recombination depends strongly on the passivation of dangling bonds by hydrogen, and hence recombination at pyramidal textured silicon increases more rapidly than at planar $\{100\}$ silicon as hydrogen is depleted.

The application of $C V$ measurements to samples of various texture indicated that there is, in deed, more defects at the surface of a textured silicon that can be accounted for by its surface area and $\{111\}$ orientation. The additional defects were predominantly neutral under flat-band conditions, making them acceptorlike when above, and donorlike when below, the $P_{L}$ distribution invoked by dangling bonds with a single oxygen back bond. The additional interface defects leads to a significant increase in the emitter saturation current density of silicon when prepared similarly to that used in high-efficiency solar cells, which are textured, lightly diffused with phosphorus, and passivated with a hydrogenated thermal oxide.

\section{ACKNOWLEDGMENTS}

The authors thank Nina de Catirat for her assistance in sample preparation. This work was funded by an Australian Research Council Linkage Grant between the Australian National University, SierraTherm Production Furnaces, and SunPower Corporation.

${ }^{1}$ R. A. Arndt, J. F. Allison, J. G. Haynos, and A. Meulenberg, Proceedings of the 11th IEEE Photovoltaics Specialists Conference, Scotttsdale, 1975 (IEEE, New York, 1975), p. 40.

${ }^{2}$ A. Goetzberger, Proceedings of the 15th IEEE Photovoltaics Specialists Conference, Kissemme, 1981 (IEEE, New York, 1981), p. 867.

${ }^{3}$ E. Yablonovitch, J. Opt. Soc. Am. 72, 899 (1982).

${ }^{4}$ P. Campbell and M. A. Green, J. Appl. Phys. 62, 243 (1987).

${ }^{5} \mathrm{C}$. R. Baraona and H. W. Brandhorst, Proceedings of the 11th IEEE Photovoltaics Specialists Conference, Scotttsdale, 1975 (IEEE, New York, 1975), p. 44.

${ }^{6}$ D. E. Lee, J. Appl. Phys. 40, 4569 (1969).

${ }^{7}$ W. P. Hirshman, Photon International 3-2009, 170 (2008)

${ }^{8}$ J. W. Müller, A. Metz, and R. Hezel, Proceedings of the 17th EU Photovoltaic Solar Energy Conference, Münich, 2001 (WIP-Renewable Energies, Münich, 2001), p. 347.

${ }^{9}$ D. L. King and M. E. Buck, Proceedings of the 22nd IEEE Photovoltaics Specialists Conference, Las Vegas, 1991 (IEEE, New York, 1991), p. 303.

${ }^{10}$ T. Lauinger, J. Schmidt, A. G. Aberle, and R. Hezel, Appl. Phys. Lett. 68, 1232 (1996).

${ }^{11}$ R. Chaoui, M. Lachab, S. Chiheub, and N. Seddiki, Proceedings of the 14th EU Photovoltaic Solar Energy Conference, Barcelona, 1997 (H. S. Stephens, Bedford, 1997), p. 812.

${ }^{12}$ Y. Nishimoto and K. Namba, Sol. Energy Mater. Sol. Cells 61, 393 (2000).

${ }^{13}$ W. Sparber, O. Schultz, D. Biro, G. Emanuel, R. Preu, A. Poddey, and D. Borchert, Proceedings of the Third World Conference on Photovoltaic Energy Conversion, Osaka, 2003 (unpublished), p. 1372.

${ }^{14}$ I. Melnyk, E. Wefringhaus, M. McCann, A. Helfricht, A. Hauser, and P.
Fath, Proceedings of the 19th EU Photovoltaic Solar Energy Conference, Paris, 2004 (WIP-Renewable Energies, Münich, 2004), p. 1090.

${ }^{15}$ P. K. Singh, R. Kumar, M. Lal, S. N. Singh, and B. K. Das, Sol. Energy Mater. Sol. Cells 70, 103 (2001)

${ }^{16}$ E. Vazsonyi, K. De Clercq, R. Einhaus, E. Van Kerschaver, K. Said, J. Poortmans, J. Szlufcik, and J. Nijs, Sol. Energy Mater. Sol. Cells 57, 179 (1999).

${ }^{17}$ T. Sun, D. Chen, and R. Chui, Proc. SPIE 4086, 116 (2000).

${ }^{18}$ O. Tabata, R. Asahi, H. Funabashi, K. Shimaoka, and S. Sugiyama, Sens. Actuators, A 34, 51 (1992).

${ }^{19}$ L. M. Landsberger, S. Naseh, M. Kahrizi, and M. Paranjape, J. Microelectromech. Syst. 5, 106 (1996).

${ }^{20}$ J. S. You, D. Kim, J. Y. Huh, H. J. Park, J. J. Pak, and C. S. Kang, Sol. Energy Mater. Sol. Cells 66, 37 (2001).

${ }^{21}$ P. Papet, O. Nichiporuk, A. Kaminski, Y. Rozier, J. Kraiem, J.-F. Lelievre, A. Chaumartin, A. Fave, and M. Lemiti, Sol. Energy Mater. Sol. Cells 90, 2319 (2006)

${ }^{22}$ M. J. Declercq, L. Gerzberg, and J. D. Meind, J. Electrochem. Soc. 122, 545 (1975)

${ }^{23}$ H. Seidel, L. Csepregi, A. Heuberger, and H. Baumgartel, J. Electrochem. Soc. 137, 3612 (1990).

${ }^{24}$ W. L. Bailey, M. G. Coleman, C. B. Harris, and I. A. Lesk, U.S. Patent No. 4137123 (Jan. 30, 1979).

${ }^{25}$ F. Llopis and I. Tobías, Prog. Photovoltaics 13, 27 (2005).

${ }^{26}$ F. Hernando, R. Guitérrez, G. Bueno, F. Recart, and V. Rodriguez, Proceedings of the Second World Conference on Photovoltaic Energy Conversion, Vienna, 1998, (WIP-Renewable Energies, Münich, 1998) p. 1321.

${ }^{27}$ J. Zhao, A. Wang, P. P. Altermatt, and M. A. Green, Appl. Phys. Lett. 66, 3636 (1995)

${ }^{28}$ A. Parretta, A. Sarno, P. Tortora, H. Yakubu, P. Maddalena, J. Zhao, and A. Wang, Opt. Commun. 172, 139 (1999).

${ }^{29}$ B. L. Sopori, Sol. Cells 25, 15 (1988).

${ }^{30}$ J. D. Hylton, A. R. Burgers, and W. C. Sinke, J. Electrochem. Soc. 151, G408 (2004).

${ }^{31}$ Y. Nishimoto, T. Ishihara, and K. Namba, J. Electrochem. Soc. 146, 457 (1999).

${ }^{32}$ A. Hauser, I. Melnyk, E. Wefringhaus, F. Delahaye, G. Vilsmeier, and P. Fath, Proceedings of the 19th EU Photovoltaic Solar Energy Conference, Paris, 2004 (WIP-Renewable Energies, Münich, 1997), p. 1094.

${ }^{33}$ J. Zhao, A. Wang, M. A. Green, and F. Ferrazza, Appl. Phys. Lett. 73, 1991 (1998).

${ }^{34}$ S. Winderbaum, O. Reinhold, and F. Yun, Sol. Energy Mater. Sol. Cells 46, 239 (1997)

${ }^{35}$ O. Schultz, G. Emanuel, S. W. Glunz, and G. P. Willeke, Proceedings of the Third World Conference on Photovoltaic Energy Conversion, Osaka, 2003 (unpublished), p. 1360.

${ }^{36}$ M. Spiegel, C. Gerhards, F. Huster, W. Jooss, P. Fath, and E. Bucher, Sol. Energy Mater. Sol. Cells 74, 175 (2002).

${ }^{37}$ A. Stesmans and V. V. Afanas'ev, J. Vac. Sci. Technol. B 16, 3108 (1998).

${ }^{38}$ S. W. Glunz, S. Sterk, R. Steeman, W. Warta, J. Knobloch, and W. Wettling, Proceedings of the 13th EU Photovoltaic Solar Energy Conference, Nice, 1995 (H. S. Stephens, Bedford, 1995), p. 409.

${ }^{39}$ P. J. Cousins and J. E. Cotter, Sol. Energy Mater. Sol. Cells 90, 228 (2006).

${ }^{40} \mathrm{~L}$. P. Johnson and K. R. McIntosh, Proceedings of the 17th International Photovoltaic Science and Engineering Conference, Fukuoka, 2007 (Toyota Technological Institute, Nagoya, 2007), p. 690.

${ }^{41}$ R. R. King, R. A. Sinton, and R. M. Swanson, IEEE Trans. Electron Devices 37, 365 (1990).

${ }^{42}$ M. J. Kerr, J. Schmidt, A. Cuevas, and J. H. Bultman, J. Appl. Phys. 89, 3821 (2001)

${ }^{43}$ H. Jin, K. J. Weber, and A. W. Blakers, Proceedings of the Fourth World Conference on Photovoltaic Energy Conversion, Waikaloa, HI, 2006 (IEEE, New York, 2006), p. 1078.

${ }^{44} \mathrm{H}$. Jin, K. J. Weber, and A. W. Blakers, Proceedings of the Fourth World Conference on Photovoltaic Energy Conversion, Waikaloa, HI, 2006 (IEEE, New York, 2006), p. 1071.

${ }^{45} \mathrm{~F}$. W. Chen, T. T. A. Li, and J. E. Cotter, Proceedings of the Fourth World Conference on Photovoltaic Energy Conversion, Waikaloa, HI, 2006 (IEEE, New York, 2006), p. 1020.

${ }^{46}$ W. L. F. Chen, "PECVD Silicon Nitride for $n$-type Silicon Solar Cells," Ph.D. thesis, UNSW, 2008.

${ }^{47}$ P. P. Altermatt, J. O. Schumacher, A. Cuevas, M. J. Kerr, S. W. Glunz, R. R. King, G. Heiser, and A. Schenk, J. Appl. Phys. 92, 3187 (2002). 
${ }^{48}$ J. Hong, W. M. M. Kessels, W. J. Soppe, A. W. Weeber, W. M. Arnoldbik, and M. C. M van de Sanden, J. Vac. Sci. Technol. B 21, 2123 (2003).

${ }^{49}$ H. Jin, K. J. Weber, and A. W. Blakers, Proceedings of the 15th International Photovoltaic Science and Engineering Conference, Shanghai, 2005 (unpublished), p. 301.

${ }^{50} \mathrm{H}$. Jin, K. J. Weber, and A. W. Blakers, Proceedings of the Fourth World Conference on Photovoltaic Energy Conversion, Waikaloa, HI, 2006 (IEEE, New York, 2006), p. 1000.

${ }^{51}$ F. Recart and A. Cuevas, IEEE Trans. Electron Devices 53, 442 (2006).

${ }^{52}$ C. H. Hsueh and A. G. Evans, J. Appl. Phys. 54, 6672 (1983).

${ }^{53}$ A. J. M. van Erven, R. C. M. Bosch, and M. D. Bijker, Prog. Photovoltaics 16, 615 (2008).

${ }^{54}$ A. G. Aberle, S. Glunz, and W. Warta, J. Appl. Phys. 71, 4422 (1992).

${ }^{55}$ K. R. McIntosh, J. H. Guo, M. D. Abbott, and R. A. Bardos, Prog. Photovoltaics 16, 279 (2008)

${ }^{56}$ International Standard, IEC 60904-3, Edition 2.0, 2008

${ }^{57}$ H. A. Macleod, Thin Film Optical Filters, 2nd ed. (Adam Hilger Ltd., Techno House, Bristol, BS1 6NX, 1986).

${ }^{58}$ Handbook of Optical Constants of Solids, edited by E. D. Palik (Academic, Orlando, 1985), Vol. 1, p. 759.

${ }^{59}$ M. A. Green and M. J. Keevers, Prog. Photovoltaics 3, 189 (1995).
${ }^{60}$ E. H. Nicollian and J. R. Brews, MOS (Metal Oxide Semiconductor) Physics and Technology (Wiley, New Jersey, 2003), Chap. 13.

${ }^{61}$ D. E. Kane and R. M. Swanson, Proceedings of the 18th IEEE Photovoltaics Specialist Conference, Las Vegas, 1985 (IEEE, New York, 1985), p. 578

${ }^{62}$ E. H. Nicollian and J. R. Brews, MOS (Metal Oxide Semiconductor) Physics and Technology (Wiley, New Jersey, 2003), Chap. 3.

${ }^{63}$ E. H. Nicollian and J. R. Brews, MOS (Metal Oxide Semiconductor) Physics and Technology (Wiley, New Jersey, 2003), p. 741.

${ }^{64}$ R. Castagne and A. Vapaille, Surf. Sci. 28, 157 (1971)

${ }^{65}$ W. Füssel, M. Schmidt, H. Angermann, G. Mende, and H. Flietner, Nucl. Instrum. Methods Phys. Res. A 377, 177 (1996).

${ }^{66}$ A. G. Aberle, Crystalline Silicon Solar Cells: Advanced Surface Passivation and Analysis (University of New South Wales, Sydney, 1999), pp. 77-78.

${ }^{67}$ C. M. Chong, "Buried Contact Solar Cells," Ph.D. thesis, University of New South Wales, 1989.

${ }^{68}$ M. J. Cudzinovic and K. R. McIntosh, Proceedings of the 29th IEEE Photovoltaics Specialist Conference, Las Vegas, 2002 (IEEE, New York, 2002), p. 70. 